\title{
Inhibition of STAT3 blocks protein synthesis and tumor metastasis in osteosarcoma cells
}

\author{
Dongqing Zuo ${ }^{1,3}$, Kristen L Shogren ${ }^{1}$, Jie Zang ${ }^{4}$, Donna E Jewison ${ }^{1}$, Brian E Waletzki ${ }^{1}$, Alan L Miller II, \\ Scott H Okuno ${ }^{2}$, Zhengdong $\mathrm{Cai}^{3}$, Michael J Yaszemski ${ }^{1}$ and Avudaiappan Maran ${ }^{1 *}$ (D)
}

\begin{abstract}
Background: Osteosarcoma is the most common bone cancer. Despite advances, molecular mechanisms associated with osteosarcoma have not been fully understood. Hence, an effective treatment for osteosarcoma has yet to be developed. Even though signal transducer and activator of transcription3 (STAT3) has been implicated, its role in pathogenesis of osteosarcoma is not fully determined. In this study, we investigated the antitumor effect of napabucasin (NP) (BBI608), an inhibitor of STAT3 on osteosarcoma in vitro and in vivo and studied the underlying molecular mechanism.
\end{abstract}

Methods: Cell viability, colony formation, apoptosis, tumor growth and metastasis assays were performed to examine the effect of NP on osteosarcoma in vitro and in vivo. Real-time RT-PCR, western analysis, immunofluorescence and reporter assays were used to monitor the expression and activity of proteins and underlying molecular pathways. Protein synthesis, co-immunoprecipitation and CAP binding assays were carried out to understand NP-mediated mechanism of actions in osteosarcoma cells.

Results: Our results show that NP treatment decreases cell viability and induces apoptosis in several osteosarcoma cell lines. NP treatment suppresses both expression and phosphorylation of STAT3 in addition to blocking STAT3-mediated transcription and downstream target proteins in osteosarcoma cells. Furthermore, NP inhibits protein synthesis through regulation of the eukaryotic initiation factor 4E (elF4E) and elF4E-binding protein 1 (4E-BP1). NP also inhibits the progression of osteosarcoma tumors and metastasis in vivo in an orthotopic tibial model of osteosarcoma.

Conclusions: Taken together, our investigation reveals that NP acts through a novel mechanism and inhibits osteosarcoma growth and metastasis, and could be investigated clinically for treating osteosarcoma patients alone or in combination with other drugs.

Keywords: Apoptosis, Napabucasin, Osteosarcoma, Protein synthesis, elF4E, 4EBP-1

\section{Background}

Osteosarcoma is a malignant bone tumor that affects children and young adults. Although it is considered a pediatric cancer, osteosarcoma has been known to affect adults and may be associated with other pathologic bone conditions. The standard clinical treatment in most countries includes presurgical chemotherapy, followed by surgical removal of the primary tumor after the second or third cycle of a year-long chemotherapy regimen [1-4]. A combination of surgery and chemotherapy has

\footnotetext{
*Correspondence: maran.avudai@mayo.edu

${ }^{1}$ Department of Orthopedic Surgery, 2-69 Medical Sciences, Mayo Clinic, 200 First St SW, Rochester, MN 55905, USA

Full list of author information is available at the end of the article
}

led to an improved survival rate in recent decades, yet about one-third of patients diagnosed with osteosarcoma develop metastatic diseases, and the survival rate is still low $[2,4-6]$. The patient prognosis is often poor, as several commonly used drugs show only modest response rates. Hence, it is vital to explore new avenues for effectively targeting and treating osteosarcoma.

STAT3 is a DNA-binding protein that belongs to the signal transducer and activator of transcription (STAT) protein family, whose biologic activities regulate several functions, including cell growth, survival, and differentiation in many cell types [7-11]. Like other STAT proteins, STAT3 is activated when cells are exposed to cytokines and growth factors. After activation, STAT3

(C) The Author(s). 2018 Open Access This article is distributed under the terms of the Creative Commons Attribution 4.0 International License (http://creativecommons.org/licenses/by/4.0/), which permits unrestricted use, distribution, and 
translocates into the cell nucleus from cytoplasm and binds to a specific sequence with target gene promoters to regulate gene transcription. Following the demonstration of constitutive activation of STAT3 in neoplastic cells, pharmacologic inhibition of STAT3 was investigated in several malignancies, including osteosarcoma $[7,8,12]$. Napabucasin (BBI608) (NP) is a small molecule that has been shown to block STAT3 and stemness in non-bone cancer cells [13-15]. As an attempt to develop alternative treatment, in this report we have studied the effect and molecular mechanism of action of NP on osteosarcoma in vitro and in vivo.

\section{Methods}

\section{Cell lines and culture}

Human osteosarcoma cell line 143B, MG63, KHOS, U2OS was obtained from the American Type Culture Collection (ATCC). Human multidrug-resistant cell line U2OSR is a kind gift from Dr. Zhenfeng Duan's laboratory (University of California, Los Angeles, CA, USA). Cells were cultured in DMEM/F12 medium and maintained at $37^{\circ} \mathrm{C}[16,17]$.

\section{Drugs and antibodies}

NP (99.9\% purity) was purchased from Abcam (Cambridge, MA). NP was dissolved in dimethyl sulfoxide (DMSO) as a 2-mM working stock solution and stored from light in an aliquot package at $-20^{\circ} \mathrm{C}$. The working concentrations used for experiments were prepared by diluting the stock solution with DMEM/F12 medium. The following antibodies were used for Western blot analysis: GAPDH, caspase-3, survivin, Bcl-xl, PARP, Bax, c-Myc, STAT3, phospho-STAT3 ${ }^{\text {Tyr705, }}$ phospho-STAT3 $^{\text {Ser727, }}$ eIF4E, phospho-4E-BP1 $1^{\text {Thr37/46, }}$ 4E-BP1, and non-phospho-4E-BP1 (Cell Signaling Technology, Danvers, MA, USA).

\section{Cell viability assay}

The human osteosarcoma cells were plated at a density of $5 \times 10^{4}$ cells per well in 24-well plates containing $1 \mathrm{~mL} /$ well medium. After allowing the cells to attach overnight, they were treated with different drugs or transfected with plasmid for 24,48 , and $72 \mathrm{~h}$. At each end of treatment or transfection, the cell viability was determined by MTS assays as described in the manufacturer's protocol (Promega, Madison, WI, USA).

\section{Cell Colony formation assay}

Cells seeded in 6-well plates (500/well) were treated with a control vehicle or NP $(0.3$ and $0.5 \mu \mathrm{M})$ for 14 days. Then cells were washed with phosphate-buffered saline (PBS), fixed with $4 \%$ paraformaldehyde, and stained with $0.1 \%$ crystal violet for $15 \mathrm{~min}$. The colonies with more than 50 cells were counted under a microscope.

\section{RNA analysis}

Total RNA was extracted from Veh and NP (3.0) $\mu \mathrm{M}-$ treated cells and isolated using trizol reagent (Invitrogen), and the mRNA levels of STAT3 and the control glyceroldehyde 3-phosphate dehydrogenase (GAPDH) were analyzed by the quantitative polymerase chain reaction (PCR) as described [18].The following primer sequences were used for PCR analysis of mRNAs: STAT3 forward, 5'-GGAGGAGTTGCAGCAAAAAG-3', STAT3 reverse, 5'-TGTGTTTGTGCCCAGAATGT-3'; GAPDH forward, 5'ATGTTCGTCATGGGTGTGAA-3'; GAPDH reverse, 5'-TGTGGTCATGAGTCCTTCCA-3.

\section{Preparation and analysis of cytoplasmic extract}

Cell lysis and preparation of cytoplasmic protein extract were carried out as described by 2 reports $[16,19]$. Briefly, cells were resuspended with lysis buffer $(0.15 \mathrm{M}$ $\mathrm{NaCl}, 5 \mathrm{mM}$ EDTA, $10 \mathrm{mM}$ Tris-Cl, 1\% Triton X-100), and protein concentrations were determined by Bradford assay. Equivalent amounts of total protein $(60 \mu \mathrm{g})$ were electrophoretically separated with $10 \%$ or $15 \%$ polyacrylamide gel and transferred to a polyvinylidene fluoride (PVDF) filter membrane. Membranes were analyzed by Western blot hybridization using primary test antibodies and control anti-glyceroldehyde 3-phosphate dehydrogenase (GAPDH) antibodies.

Immunoprecipitation analysis was carried out as described by Kennedy and colleagues [20]. Cytoplasmic protein extracts containing $60 \mathrm{mg}$ of protein were immunoprecipitated with anti-4E-BP1 antibodies and analyzed by Western blot using anti-eIF4E antibodies. The quantitation of protein signals was done using densitometer and Quantity One 4.5.2 software (BioRad, Hercules, CA, USA).

\section{Immunofluorescence assay}

Osteosarcoma cells were grown on coverslips and treated with vehicle or NP for $12 \mathrm{~h}$ and fixed with $4 \%$ paraformaldehyde. They were then permeabilized with $0.1 \%$ Triton X-100 in PBS. Samples were blocked with $1 \%$ bovine serum albumin for $30 \mathrm{~min}$, followed by incubation with indicated primary antibodies at $4{ }^{\circ} \mathrm{C}$ overnight. After 3 washes with PBS, cells were probed with Alexa Fluor 488 secondary antibody (ThermoFisher Scientific, Waltham, MA, USA) for $1 \mathrm{~h}$ at room temperature. The nuclei were stained by 4', 6-diamidino-2-phenylindole (DAPI) and images were acquired with a fluorescence microscope.

\section{Hoechst 33258 assay}

The Hoechst assay was used to evaluate apoptotic cell death after NP treatment. 143B and MG63 cells were seeded on coverslips at a density of $2.5 \times 10^{5}$ cells per well in 6-well plates and exposed to vehicle or NP 
$(3.0 \mu \mathrm{M})$ for $24 \mathrm{~h}$. Hoechst staining and assays were carried out as described by previously [19].

\section{Flow Cytometry}

Osteosarcoma cells were cultured in 6-well plates $(2.5 \times$ $10^{5} /$ well) and treated as indicated for $24 \mathrm{~h}$. Cell apoptosis was assayed using the Annexin V-FITC apoptosis detection kit (BD Biosciences, San Jose, CA, USA). Dual-parameter dot plots combining Annexin V-FITC/PI revealed live cells (Annexin V-/PI-), early apoptotic cells (Annexin V+/PI-), late apoptotic cells (Annexin $\mathrm{V}+/ \mathrm{PI}+$ ), and necrotic cells (Annexin $\mathrm{V}-/ \mathrm{PI}+$ ), respectively, in the lower left, lower right, upper right, and upper left quadrants.

\section{Gamma-activated sequence luciferase reporter gene assay} Cells were plated at a density of $8 \times 10^{4}$ cells per well in 12 -well plates and left overnight to settle. The next day, cells were transfected using FuGene (Promega, Madison, WI, USA) with $4 \mu \mathrm{g}$ of gamma activated sequence (GAS) reporter plasmid DNA according to manufacturer protocol. After $24 \mathrm{~h}$ of transfection, cells were treated with vehicle, interferon (IFN)- $\gamma(2,000 \mathrm{U} / \mathrm{ml})$, and NP $(3.0 \mu \mathrm{M})$ for $24 \mathrm{~h}$. At the end of treatment, the cells were harvested and assayed for luciferase activity as described (Luciferase Assay kit, Promega). Control plasmids containing renilla luciferase were used to normalize luciferase units.

\section{Protein degradation assay}

Osteosarcoma cells were plated and $24 \mathrm{~h}$ later, $2 \mu \mathrm{Ci}$ of

${ }^{14} \mathrm{C}$-L-valine was added and maintained for $24 \mathrm{~h}$. Cells were then rinsed and treated with vehicle and $10 \mu \mathrm{M} N P$ in fresh media. The media were collected at different time points. The cells were lysed, and radioactivity was determined by precipitating with $10 \%$ trichloroacetic acid and measured in a scintillation counter. The protein degradation was determined by calculating the ratio of label in the media to the cells.

\section{Protein synthesis $\left({ }^{3} \mathrm{H}\right.$-Leucine incorporation)}

The rate of protein synthesis was determined as described by Constantinou and Clemens [21]. Briefly, following vehicle and NP treatment and pulse, labeling of osteosarcoma cells was carried out for $1 \mathrm{~h}$ with $10 \mathrm{mCi} / \mathrm{mL}$ of radiolabeled leucine. The cells were harvested, lysed, and precipitated with $10 \%$ trichloroacetic acid (TCA). The radioactivity was measured by scintillation counting.

\section{Cap-binding assay}

Cap-binding assay by m7GTP Sepharose chromatography was performed using osteosarcoma cell lysate $(100 \mu \mathrm{g}$ protein) and $20 \mathrm{~mL}$ of packed m7GTP Sepharose beads to capture eukaryotic initiation factor 4E (eIF4E) and its binding proteins as previously described [22] .

\section{Nude mouse tibia Orthotopic tumor model}

All animal procedures were performed in accordance with a protocol approved by the Institutional Animal Care and Use Committee (IACUC) at Mayo Clinic. Four-week-old female $\mathrm{BABL} / \mathrm{c}$ nude mice were used for this study, and $143 \mathrm{~B}$ osteosarcoma cells $\left(1.5 \times 10^{6}\right)$ in $20 \mu \mathrm{L}$ of PBS was injected into the right tibial medullary cavity using a 25 -gauge needle and a $100-\mu \mathrm{L}$ syringe to establish an orthotopic osteosarcoma in vivo model. Two weeks after injection of tumor cells, the mice were randomly allocated to the vehicle (DMSO) group $(n=10), 10 \mathrm{mg} / \mathrm{kg} \mathrm{NP}$ group $(n=10)$, and $20 \mathrm{mg} / \mathrm{kg} \mathrm{NP}$ group $(\mathrm{n}=10)$. Each mouse in the 2 NP groups was given an NP intraperitoneal injection every 3 days. The vehicle-group mice were injected with $100 \mu \mathrm{L}$ of PBS with $10 \%$ DMSO the same way. The tumor volume and body weight of the animals were measured before injection using the formula: tumor volume $=\left(\right.$ length $\times$ width $\left.^{2}\right) 0.5$. Following 8 continuous injections, the mice were euthanized. Tumor legs were dissected and stored in liquid nitrogen or fixed in formalin for analysis.

Lung tissues were harvested, fixed in 10\% formalin, and embedded in paraffin. Metastases in the lung were examined by gross observation and histologic assessment, as shown earlier [23]. Briefly, visible macrometastases (tumor nodules) were counted and measured with the aid of a dissecting microscope. Mice lungs were embedded in paraffin, followed by sectioning and staining with hematoxylin and eosin to detect for pulmonary metastases. Averages were determined from the total number of metastases per section. Quantity and quality of bone across the tibiae were analyzed ex vivo using Skyscan 1272 micro-computed tomography (Micro-CT) scanner (Bruker, Kontich, Belgium). Micro-CT projections were reconstructed and the bone volume was determined in 100 projections (slices) using the NRecon software (Bruker).

\section{Statistical analysis}

Statistical analysis was performed with GraphPad Prism 5 (La Jolla, CA, USA). All values are expressed as mean $\pm \mathrm{SE}$. Comparisons between groups were made using the Student $t$ test and 2-way ANOVA. $P<0.05$ was considered statistically significant.

\section{Results}

NP blocks osteosarcoma cell growth and Colony formation To determine whether NP blocks osteosarcoma growth, the MTS-based cell viability assay was carried out at 24 to $72 \mathrm{~h}$ after NP treatment in various osteosarcoma cell lines. The results show a dose-dependent effect on cell survival in several osteosarcoma cells (Fig. 1a). In the case of 143B cells, cell survival was reduced at 24, 48, and $72 \mathrm{~h}$, respectively, to $84 \%, 52 \%$, and $50 \%$ by $0.5 \mu \mathrm{M}$; 


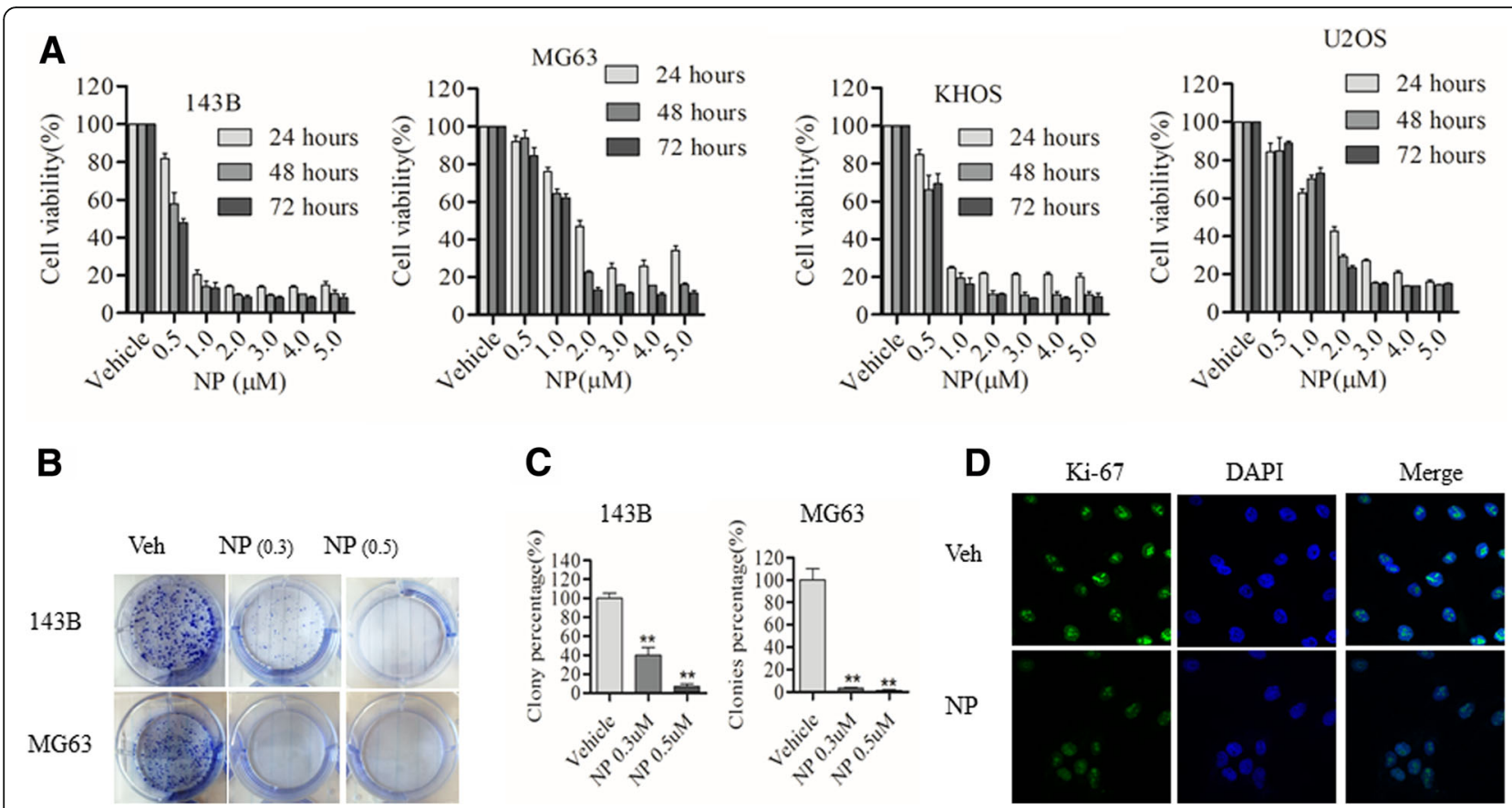

Fig. 1 NP decreases cell viability and proliferation of human osteosarcoma cells. a, Human osteosarcoma cells (143B, MG63, U2OS, KHOS) were treated with vehicle (Veh) $(0.1 \%$ DMSO) or NP at various concentrations for 24,48 , and 72 h, and cell viability was measured by MTS assay as described in the Methods section of the text. $\mathbf{b}$ and $\mathbf{c}$, The cell colony formation assay was carried out in $143 \mathrm{~B}$ and MG63 treated with Veh or NP

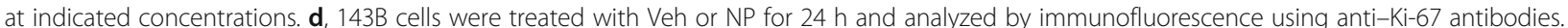
The data are representative of 3 independent experiments. ${ }^{*} P<0.05$ versus vehicle control; ${ }^{* *} P<0.01$ versus vehicle control

to $18 \%, 11 \%$, and $10 \%$ by $1 \mu \mathrm{M}$; to $13 \%, 8.9 \%$, and $9.5 \%$ by $2 \mu \mathrm{M}$; to $13 \%, 9.2 \%$, and $9 \%$ by $3 \mu \mathrm{M}$; to $12.9 \%, 9.8 \%$, and $8.9 \%$ by $4 \mu \mathrm{M}$; and to $13 \%, 8 \%$, and $9.8 \%$ by $5 \mu \mathrm{M}$, compared to the vehicle control. MG63 cell survival was reduced at 24,48 , and $72 \mathrm{~h}$, respectively, to $78.5 \%, 62 \%$, and $60 \%$ by $0.5 \mu \mathrm{M}$; to $50 \%, 23 \%$, and $12 \%$ by $1 \mu \mathrm{M}$; to $22 \%$, $16 \%$, and $11 \%$ by $2 \mu \mathrm{M}$; to $29 \%, 15 \%$, and $9.8 \%$ by $3 \mu \mathrm{M}$; to $32 \%, 15 \%$, and $10 \%$ by $4 \mu \mathrm{M}$; and to $30 \%, 14 \%$, and $10 \%$ by $5 \mu \mathrm{M}$, compared to the vehicle control. Similarly, the results show that KHOS cell survival was reduced at 24, 48, and $72 \mathrm{~h}$, respectively, to $87 \%, 73 \%$, and $74 \%$ by $0.5 \mu \mathrm{M}$; to $25 \%, 22 \%$, and $13 \%$ by $1 \mu \mathrm{M}$; to $21 \%, 8.9 \%$, and $11 \%$ by $2 \mu \mathrm{M}$; to $20.6 \%, 8.6 \%$, and $9 \%$ by $3 \mu \mathrm{M}$; to $20 \%, 9 \%$, and $9.5 \%$ by $4 \mu \mathrm{M}$; and to $18 \%, 8.8 \%$, and $11 \%$ by $5 \mu \mathrm{M}$, compared to the vehicle control. In U2OS, cell survival was reduced at 24,48 , and $72 \mathrm{~h}$, respectively, to $65 \%, 72 \%$, and $76 \%$ by $0.5 \mu \mathrm{M}$; to $45 \%, 28.5 \%$, and $24.6 \%$ by $1 \mu \mathrm{M}$; to $28 \%$, $14.8 \%$, and $14 \%$ by $2 \mu \mathrm{M}$; to $19.9 \%, 13.4 \%$, and $13.8 \%$ by $3 \mu \mathrm{M}$; to $14.9 \%, 14 \%$, and $15 \%$ by $4 \mu \mathrm{M}$; and to $14 \%, 13.5 \%$, and $14.5 \%$ by $5 \mu \mathrm{M}$, compared to the vehicle control.

In order to evaluate the effect of NP on osteosarcoma cell proliferation, we carried out colony-formation assays in 143B and MG63 cells following NP treatment. We found that considerably fewer colonies were detected after treatment with 0.3 and $0.5 \mu \mathrm{M} \mathrm{NP}$ in $143 \mathrm{~B}$ and MG63 cells, substantiating the inhibition of cell proliferation (Fig. 1b and c). In addition, we found that the expression of Ki-67, a cellular marker for proliferation, was suppressed following NP treatment for $24 \mathrm{~h}$ in 143B osteosarcoma cells (Fig. 1d).

NP induces apoptotic cell death in human osteosarcoma cells To determine whether NP-mediated cell death was due to the induction of apoptosis, we measured apoptosis in osteosarcoma cells with Hoechst dye and Annexin V-FITC/PI staining in the presence and absence of NP treatment. Hoechst dye-positive cells increased in the presence of NP indicating apoptosis (Fig. 2a). Annexin V-FITC/PI staining analysis revealed that NP treatment at $24 \mathrm{~h}$ induced apoptosis in a dose-dependent manner (Fig. 2b). We further verified the induction of apoptosis by Annexin V-FITC/PI staining of cells treated with various concentrations of NP. As shown in Fig. $2 b$ and c, $\mathrm{NP}$ induced apoptosis in a dose-dependent manner in both $143 \mathrm{~B}$ and MG63 cells. At 1,3 , and $5 \mu \mathrm{M}$ concentrations of NP, approximately $23 \%, 35 \%$, and $89 \%$ of cells were apoptotic in 143B cells and $7 \%, 40 \%$, and $44 \%$ of cells were apoptotic in MG63 cells, respectively (Fig. 2c and d). To further confirm these outcomes, we investigated the molecular pathways involved in the stimulation of apoptosis. As shown in Fig. 2e and f, NP activated caspase- 3 and PARP cleavage in a dose- and time-dependent manner. 


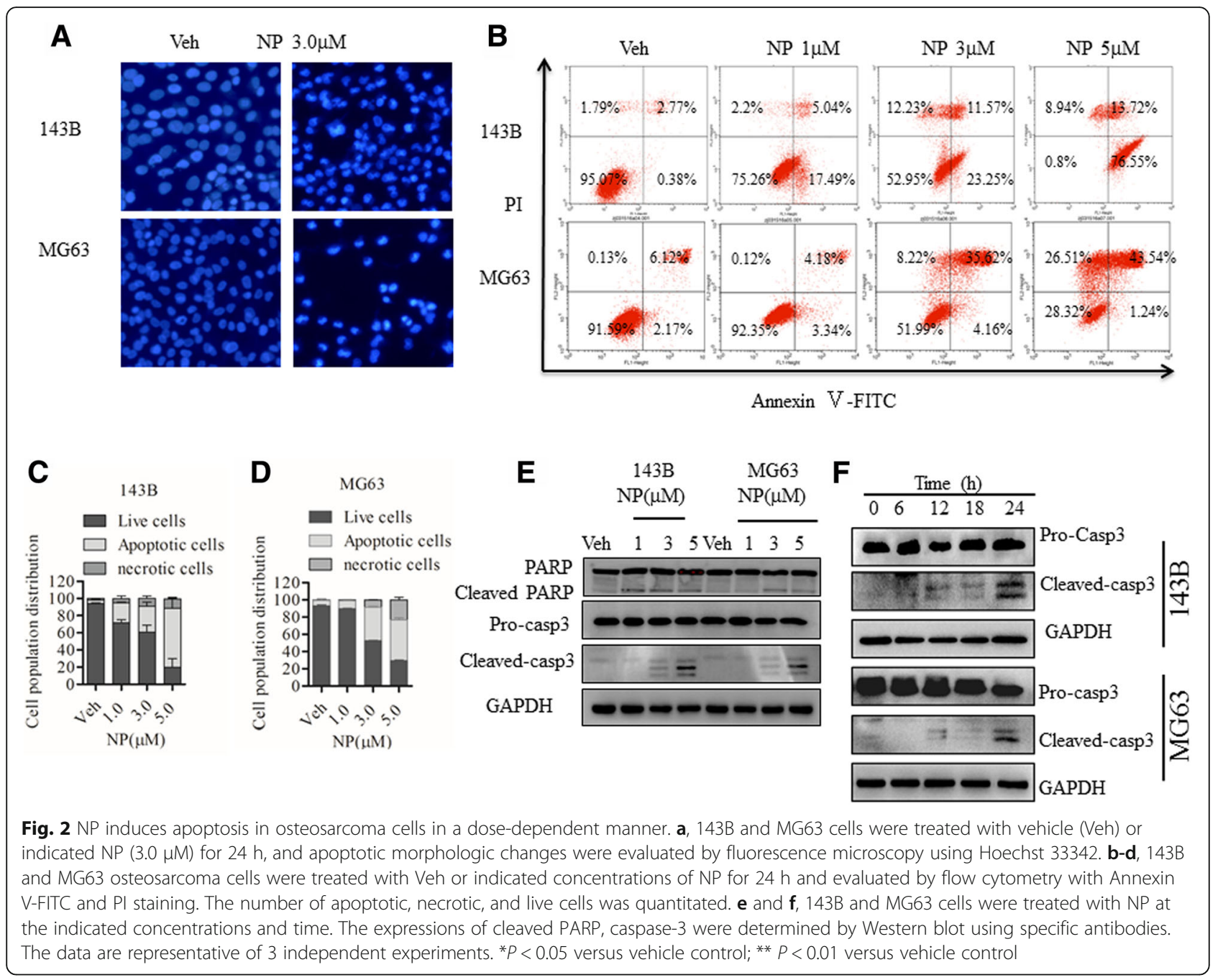

NP inhibits IFN- $\gamma$-regulated STAT3 expression and activity gene induction

NP is known for the inhibition of STAT3 phosphorylation and activation in other cell types. Here, we evaluated the NP effect on osteosarcoma cells. Immunofluorescence in 143B osteosarcoma reveals that NP at $3 \mu \mathrm{M}$ decreased the number of p-STAT3-positive cells; Western blot analysis showed that NP treatment markedly blocked STAT3 activation and phosphorylation of STAT3 in both $\mathrm{Tyr}^{705}$ and $\mathrm{Ser}^{727}$ sites in 143B and MG63 osteosarcoma cells (Fig. 3a and b). NP at 1, 3 , and $5 \mu \mathrm{m}$ decreased STAT3 levels in 143B cells and in MG63 cells, respectively (Fig. 3b). It has been demonstrated that IFN- $\gamma$ activates STAT3 phosphorylation and STAT3-dependent transcription. To further study the effect of NP on STAT3 activation in osteosarcoma cells, we determined its effect on IFN- $\gamma$-dependent regulation and activation of STAT3. Western blot analysis showed that NP treatment blocks IFN- $\gamma$-activated induction of STAT3 expression in both 143B and MG63 osteosarcoma cells (Fig. 3c). The control GAPDH expression is not affected by
IFN- $\gamma$ and NP treatments (Fig. 3c). In addition, GAS luciferase reporter assays show that IFN- $\gamma$-dependent GAS luciferase activity is decreased from 25 -fold to 11 -fold in the presence of NP co-treatment in 143B cells (Fig. 3d). Similarly, in MG63 cells, GAS luciferase activity, which was 18 -fold in the presence of IFN- $\gamma$ treatment, was decreased to 5-fold when IFN- $\gamma$ and NP were treated together. Our results also show that NP on its own does not have any effect on GAS-dependent luciferase activity (Fig. 3d).

STAT3 has been previously implicated in the regulation of anti- or pro-apoptotic regulators. Our results showed that c-Myc, survivin, vascular endothelial growth factor (VEGF)-A, and Bcl-xl were downregulated following NP treatment in osteosarcoma cells (Fig. 3e and f).

\section{NP treatment Downregulates protein synthesis initiation factors elF4E and 4E-BP1 and blocks protein synthesis in osteosarcoma cells}

In order to determine whether NP has a direct effect on the mRNA levels of STAT3, we carried out quantitative 


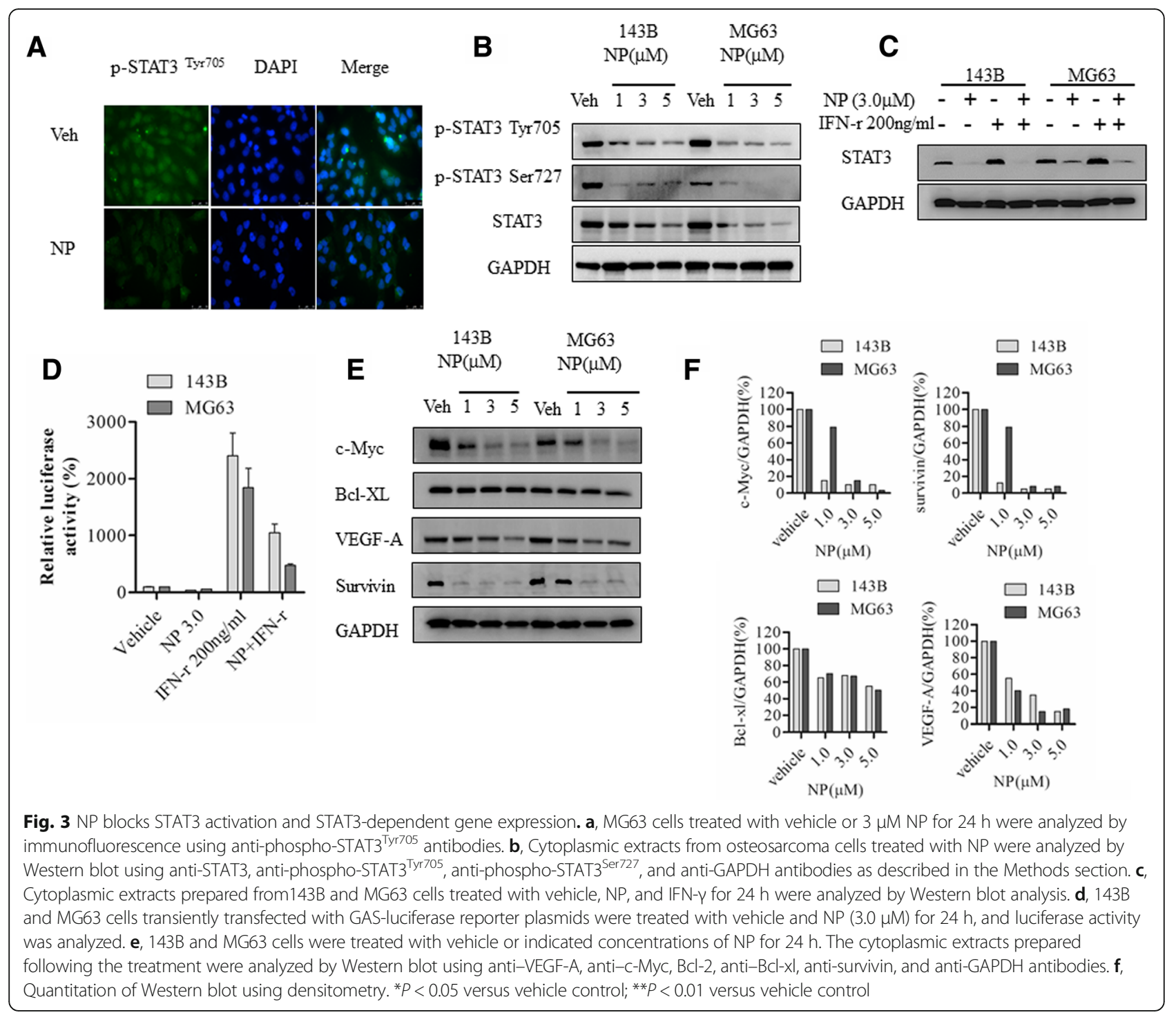

polymerase chain reaction (PCR). The results showed that NP treatment displays only minimal changes after $24 \mathrm{~h}$, and STAT3 mRNA levels decreased by $0.95 \pm$ 0.3 -fold and $0.90 \pm 0.2$-fold in 143B and MG63 cells, respectively (Fig. 4a). To determine whether NP-induced changes are associated with translational changes, we investigated the effect of NP in the presence and absence of cycloheximide (CHX) in osteosarcoma cells. The results showed that NP treatment promotes $\mathrm{CHX}$-mediated protein synthesis inhibition (Fig. 4b). Further, we used 2 protein degradation inhibitors to verify this finding. Our results showed that neither proteasome inhibitor MG132 (Fig. 4c and d) nor lysosome inhibitor Bafilomycin A1 (Baf-A1) (Fig. 4e and f) could restore NP-mediated STAT3 inhibition. Additional studies to investigate the effect of NP treatment on protein degradation using a ${ }^{14} \mathrm{C}$ labeling showed that the NP plus MG132 treatment group displayed exactly the same ${ }^{14} \mathrm{C}$ release as the MG132 treatment alone (Fig. 4g), indicating that NP actions do not involve protein degradation.

We then evaluated the effect of NP on protein synthesis in osteosarcoma cells through ${ }^{3} \mathrm{H}$-labeling studies. The results showed that the rate of protein synthesis is considerably lowered following $24 \mathrm{~h}$ of NP treatment in $143 \mathrm{~B}$ and MG63 cells to $1 \%$ and $8 \%$, respectively, compared to vehicle (Fig. 5a). Previous results showed that a decrease in protein synthesis is coupled with a block in protein synthesis at the level of translation initiation. To determine whether NP regulates protein synthesis block at the level of initiation, we investigated the regulation of eIF4E and eIF4E-binding protein 1 (4E-BP1) in osteosarcoma cells. Analysis of cytoplasmic extracts by co-immunoprecipitation studies from vehicle- and NP-treated osteosarcoma cells show that NP increased the binding of $4 \mathrm{E}-\mathrm{BP} 1$ to eIF4E at $16 \mathrm{~h}$ in $143 \mathrm{~B}$ and MG63 cells, respectively (Fig. 5b). Also, the cap-binding 


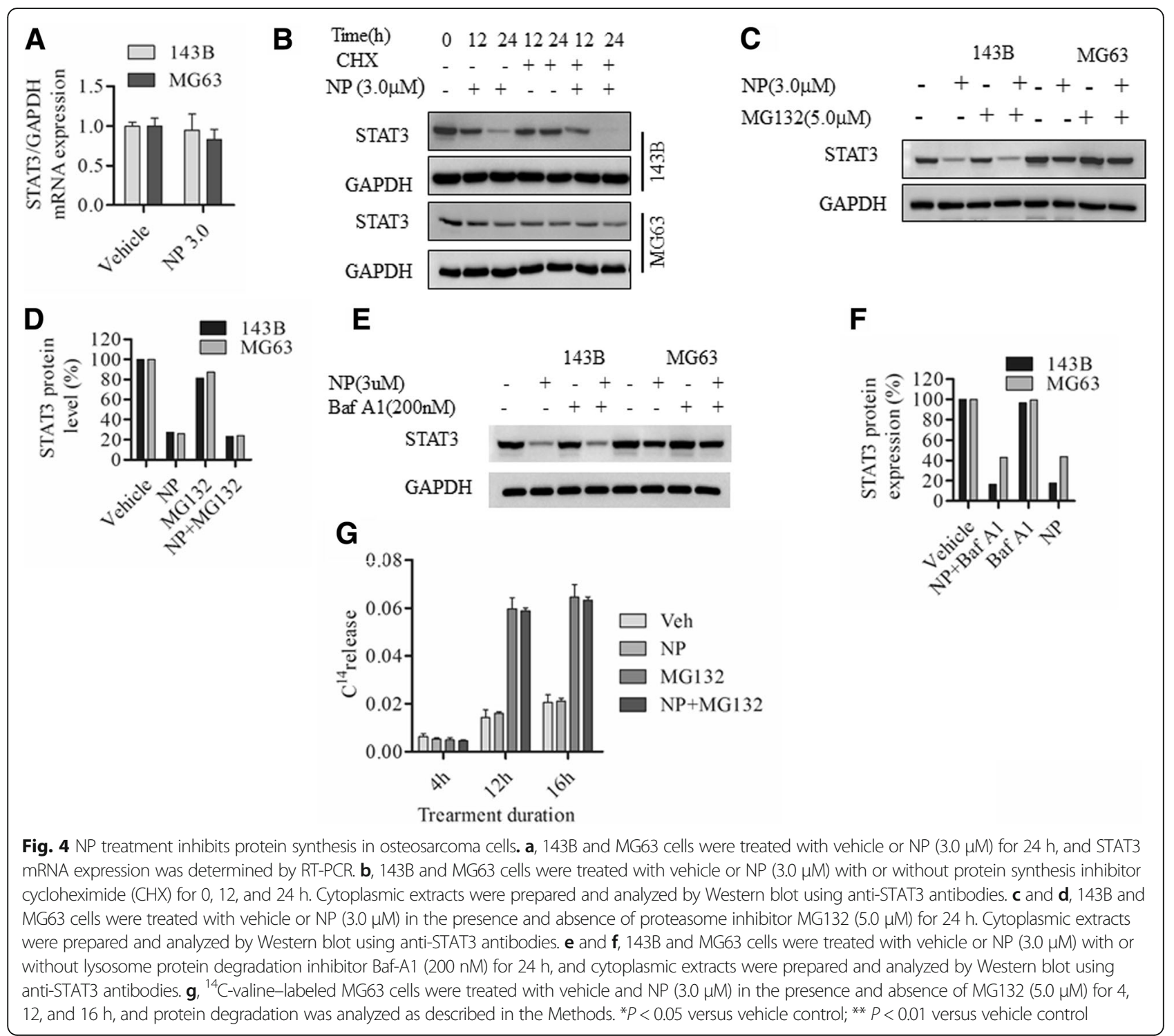

assays show that NP treatment resulted in decreased binding of eIF4E to cap structure (Fig. 5c). Western blot analysis revealed that NP does not affect the levels of eIF4E and control protein GAPDH, though it does modulate 4E-BP1 protein levels in osteosarcoma cells at the level of phosphorylation (Fig. 5d). Using specific phospho (anti-phospho-4E-BP1) and non-phospho (anti-nonphospho 4E-BP1) antibodies that recognize hypo- and hyper-phosphorylated proteins (Fig. 5d, arrows) and non-phosphorylated proteins (Fig. 5D, dotted lines) and the total antibody (anti-4E-BP1) that recognizes both the phosphorylated and non-phosphorylated forms, we demonstrated that NP increases non-phosphorylated protein levels of 4E-BP1 levels (Fig. 5d).

\section{NP inhibits growth of osteosarcoma in vivo}

The in vivo anti-tumor effect of NP was determined using nude mouse models of osteosarcoma developed through intratibial injection of osteosarcoma cells. Our results show that intraperitoneal administration of NP at doses of 10 and $20 \mathrm{mg} / \mathrm{kg}$ resulted in decreased tumor volume to $43.8 \%$ and $60 \%$, respectively (Fig. 6a). Notably, 10 and $20 \mathrm{mg} / \mathrm{kg}$ of NP treatment induced 6\% and 14\% weight loss in mice, respectively, following treatment (Fig. 6b). Additionally as shown in Fig. 6c and d, NP administration inhibited osteosarcoma lung metastasis in nude mice. Hematoxylin and eosin staining and quantitation of stained lung sections revealed $60 \%$ and $80 \%$ decreases in the number of metastatic nodules in animals treated with 10 and $20 \mathrm{mg} / \mathrm{kg}$ of NP, respectively (Fig. 6c and d).

Micro-CT analysis of mouse bone specimen was used to quantify the effect of NP on bone destruction and osteolysis. The results showed bone erosion in tumor legs treated with vehicle and further showed that osteosarcoma-induced osteolysis was reduced in the 

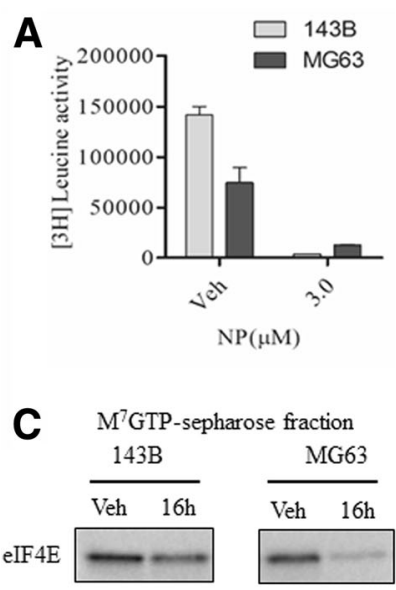

B

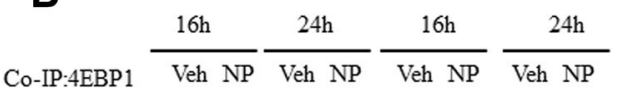

eIF4E

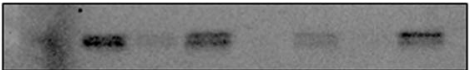

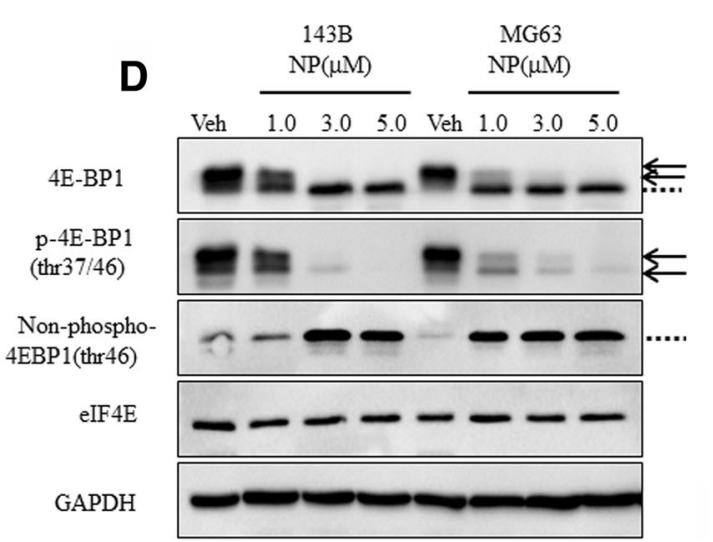

Fig. 5 NP regulates elF4E and 4E-BP1 functions in osteosarcoma cells. a, Protein synthesis was measured following vehicle and NP treatment in $143 \mathrm{~B}$ and MG63 cells at $24 \mathrm{~h}$ through pulse labeling with ${ }^{3} \mathrm{H}$-leucine. b. Cytoplasmic extracts were prepared from $143 \mathrm{~B}$ and MG63 osteosarcoma cells at 16 and $24 \mathrm{~h}$ following Veh and NP $(3.0 \mu \mathrm{M})$ treatment. The extracts were subjected to immunoprecipitation (IP) with anti-4E-BP1 antibodies (b) or cap-binding (c) and analyzed by Western blot analysis using anti-elF4E antibodies. d, Cytoplasmic extracts were analyzed by Western blot using anti-4E-BP1, anti-phosph-4EBP1Thr37/46, anti-non-phospho-4E-BP1, anti-elF4E, and anti-GAPDH antibodies. Arrows represent phosphorylated proteins and dotted lines represent non-phosphorylated proteins

bones of mice that were treated with NP (Fig. 6e). The bone volume of the distal tibia injected with NP was increased by $33 \%$, suggesting that NP treatment in mice reduced tumor-induced bone destruction (Fig. 6e).

\section{Discussion}

Apart from mediating downstream signaling of cytokines, growth factors, and transcriptional regulations, STAT3 proteins have been implicated in several cellular processes, including cell proliferation and tumorigenesis $[7-9,12,24]$. In this report, we showed that the STAT3 inhibitor NP induces cell death and inhibits STAT3 protein expression, phosphorylation, and transcriptional activity in osteosarcoma cells. Also, this study showed that NP-mediated regulation of STAT3 in osteosarcoma cells involves down regulation of protein synthesis initiation factors and inhibition of protein synthesis. Additionally, NP treatment blocks osteosarcoma growth in nude mice models. These results demonstrate novel downstream mechanisms of STAT3 and reveal that NP, which effectively blocks osteosarcoma growth in vitro and in vivo, could be further explored clinically in the control of osteosarcoma tumors and metastasis.

Activation of STAT3 and its role as an oncogene has been demonstrated in many tumors [8, 24]. Several studies have employed the inhibition of STAT3 as a beneficial anticancer strategy to target human tumors of both solid and hematologic origin [24]. Recently, NP has been used to target numerous malignancies. Our results show that NP blocks cell growth and decreases cell viability in several osteosarcoma cells. Furthermore, the proliferation marker Ki-67 is downregulated in NP-treated osteosarcoma cells. These observations are substantiated by decreased tumorigenicity and colony formation in the presence of NP treatment. Evaluation of the mechanism of growth inhibitory actions of NP in MG63 and 143B osteosarcoma cells suggests that NP induces apoptosis and cleavage of molecular markers, PARP, and Pro-Caspases 3. Thus, these results demonstrate that anti-tumorigenic effects of NP involve inhibition of cell proliferation and induction of apoptosis in osteosarcoma cells.

STAT3 is constitutively activated in many tumors, including osteosarcoma [24-26]. STAT3 activation can occur through phosphorylation of tyrosine 705 or serine 727. It has been demonstrated by earlier investigations that tyrosine phosphorylation contributes to translocation of STAT3 to the nucleus, activation of target genes, and tumorigenesis. In addition, reports show that phosphorylation at serine 727 is required for the highest 


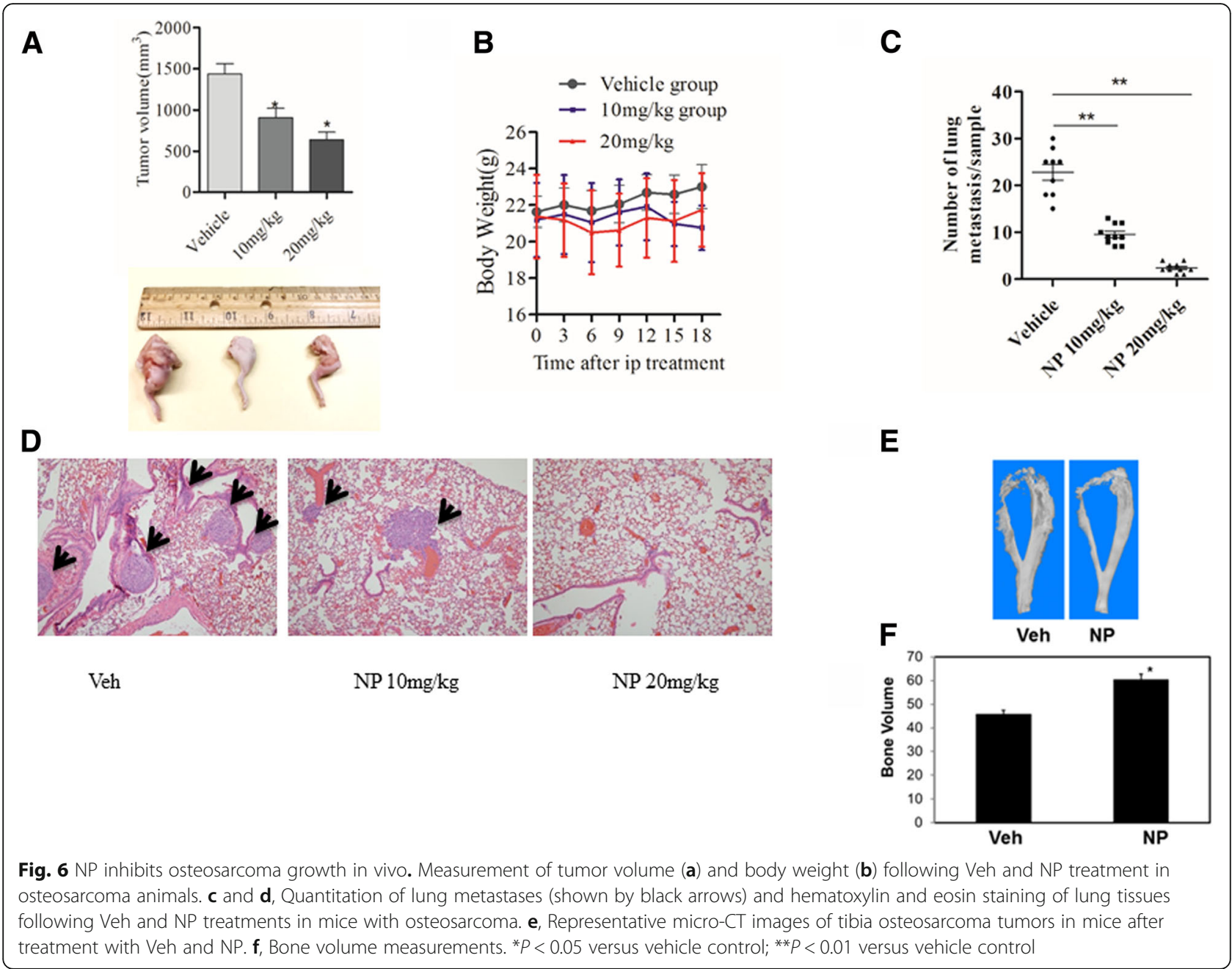

transcriptional activity of STAT3 [27] and stimulates prostate tumorigenesis independent of tyrosine 705 phosphorylation [28]. Furthermore, sources suggest that the constitutive phosphorylation of STAT3 at serine 727 is detected in various types of human malignancies and is essential for tumor cell growth and invasion [29, 30]. Current findings show that NP regulates STAT3 at multiple levels and blocks both tyrosine and serine phosphorylation of STAT3 proteins in addition to decreasing its expression levels in osteosarcoma cells. Our results also show that cytokine (IFN- $\gamma$ )-mediated activation of STAT3 activity and STAT3-dependent transcription in osteosarcoma cells are blocked by NP. Previous reports indicate that STAT3 can regulate several genes, including anti- or pro-apoptotic regulators. Our results show that $\mathrm{c}-\mathrm{Myc}$, survivin, VEGF-A, and Bcl-xl were downregulated following NP treatment in osteosarcoma cells. These observations are in agreement with previous reports in osteosarcoma and other cancers, which show that inhibition of STAT3 leads to decreased expression of survivin, VEGF-A, and Bcl-xl. Recently, Oi et al. showed that a plant-derived STAT3 inhibitor, cucurbitacin, suppresses the expression of c-myc and survivin proteins [31]. Also, siRNA-mediated inhibition of STAT3 leads to the downregulation of survivin and VEGF-A in canine osteosarcoma cells [25]. NP treatment has been shown to downregulate survivin and c-Myc in prostate cancer models [14, 15]. Thus, our current study shows that c-Myc, VEGF-A, and survivin are downregulated in osteosarcoma cells following the inhibition of STAT3 activity and confirms that molecular signaling downstream of STAT3 is blocked.

The NP-mediated effect does not require new protein synthesis, as shown by cycloheximide co-treatment. Also, it is not affected by proteasome inhibitor MG132 treatment and does not involve proteolytic degradation pathways. Our studies reveal that NP treatment leads to a block in protein synthesis in 143B and MG63 osteosarcoma cells. Previous reports showed that the regulation of protein synthesis at the initiation level plays an important role in the control of tumor cell proliferation [32-34]. The role of the protein synthesis initiation 
factor, eIF4E, has been studied in detail in tumor cells $[32,35]$. The eIF4E is the $5^{\prime}$ cap-binding protein that controls ribosome recruitment at the mRNA $5^{\prime}$ end, whose activity is inhibited by 4E-BPs (eIF4E-binding proteins). The $4 \mathrm{E}-\mathrm{BP}$ regulates the eIF4E ability to form a cap-binding complex. The 4E-BPs are phosphorylated in response to cytokines, growth factors, and anti-tumor compounds [32, 35]. When 4E-BP is hypophosphorylated, it can sequestrate eIF4E and block translational initiation by blocking the interaction of eIF4E with eIF4G. The eIF4E is a rate-limiting factor of the eIF4F protein complex and is essential for all mRNAs to be translated into proteins. The protein complex binds to 7-methyl-guanosine-triphosphate cap structure in mRNAs, which further facilitates binding to ribosomes and cap-dependent protein synthesis [33, 35]. The eIF4D also requires cap binding for its ability to promote growth and to transform cells. Our results reveal an increased binding of eIF4E and 4E-BP1 and decreased binding of eIF4E to 7-methyl-guanosine cap structure in the presence of NP treatment. These observations are further confirmed by increased levels of non-phospho $4 \mathrm{E}-\mathrm{BP} 1$ and decreased levels of phospho 4E-BP1 in the presence of NP treatment in osteosarcoma cells. Studies reveal that, compared to normal cells, tumor cells rely more on cap-dependent protein synthesis and synthesis of oncogenic proteins [21, 33, 35]. In addition, dysregulated transport of mRNAs of oncogenes appears to be the reason for the oncogenic functions of eIF4E. Overall, these studies indicate that NP could work, partly, through the regulation of protein synthesis. Our findings, which reveal a novel downstream regulatory mechanism for STAT3, is corroborated by the pleotropic functions of STAT3 in various cell types, contributing to transcriptional regulation, mitochondrial activities, interaction with DNA methyl transferase 1, and tumorigenesis [36, 37]. This observation is also in agreement with earlier reports regarding the role of eIF4E and 4E-BPs in osteosarcoma in vitro and in vivo. A previous report showed that eIF4E could work downstream of critical antitumor pathways [22]. Additionally, evidence points out that STAT3 could be co-regulated with eIF4E in human malignancies [38]. Thus, given the apparent role of the eIF4E pathway in malignant transformation, it is possible that NP-induced STAT3-dependent control of osteosarcoma cell functions could, in part, work through the regulation of protein synthesis. Further work is needed to understand the complete mechanisms and target gene mRNAs that are regulated at the level of protein synthesis initiation following NP treatment.

Other than standard chemotherapy, no new drug has been introduced to treat osteosarcoma in the past 2 decades. Recently, the advancement of pathway-targeted drugs has offered hope in blocking tumorigenic pathways in osteosarcoma. Our work shows that NP treatment blocks tumor growth, metastasis and tumor-induced osteolysis in animals with osteosarcoma. Thus, our work, which reveals that NP blocks STAT3-dependent tumor progression and metastasis of osteosarcoma, could be useful in targeting osteosarcoma.

\section{Conclusions}

Our studies show that NP-mediated inhibition of STAT3 blocks osteosarcoma growth in vitro and in vivo. NP-mediated anti-tumor effects involve downstream control of protein synthesis. Taken together, our findings reveal that NP actions involve novel mechanisms in osteosarcoma, and it could be worthy of further clinical evaluation in the treatment of osteosarcoma alone or in combination with other chemotherapeutic agents.

\section{Abbreviations}

4E-BP1: elF4E-binding protein 1; CHX: Cycloheximide; DOX: Doxorubicin; elF4E: Eukaryotic initiation factor 4E; GAS: Gamma activated sequence;

IFN: Interferon; micro-CT: micro-computed tomography; NP: Napabucasin; STAT3: Signal transducer and activator of transcription3

\section{Acknowledgments}

The authors thank Mr. Jim Herrick for his inputs and the Mayo Clinic Biomaterials and Histomorphometry Core laboratory for histological and micro-CT analyses.

\section{Funding}

This work was supported by funding from Mayo Clinic, the Rein in Sarcoma Foundation (AM), the National Institutes of Health R34 grant DE025593 (MJY) and National Natural Science Foundation of China grant 81802985 (DZ).

\section{Availability of data and materials}

The datasets used and analyzed during the current study are available upon reasonable request.

\section{Authors' contributions}

All authors read and approved the final version of the manuscript. DZ, ZC, MJY and AM conceived the idea and designed the experiments. DZ, KLS and $J Z$ performed the in vitro studies and assays. DZ, KLS, DEJ and AM carried out the animal studies. KLS, DEJ, BEW and ALM contributed to the tissue analysis. DZ, KLS, SHO, ZC, MJY and AM analyzed the data and interpreted the results: DZ and AM wrote the paper.

Ethics approval and consent to participate

The animal studies described were approved by the IACUC of Mayo Clinic.

Consent for publications

Not applicable.

\section{Competing interests}

The authors declare that they have no competing interests.

\section{Publisher's Note}

Springer Nature remains neutral with regard to jurisdictional claims in published maps and institutional affiliations.

\section{Author details}

'Department of Orthopedic Surgery, 2-69 Medical Sciences, Mayo Clinic, 200 First St SW, Rochester, MN 55905, USA. ²Division of Medical Oncology, Mayo Clinic, Rochester, MN, USA. ${ }^{3}$ Department of Orthopedics, Shanghai General Hospital, Shanghai Jiao Tong University, Shanghai, China. ${ }^{4}$ Musculoskeletal Tumor Center, People's Hospital, Peking University, Beijing 100044, China. 
Received: 10 August 2018 Accepted: 20 September 2018

Published online: 04 October 2018

\section{References}

1. Kumar R, Kumar M, Malhotra K, Patel S. Primary osteosarcoma in the elderly revisited: current concepts in diagnosis and treatment. Curr Oncol Rep. 2018;20(2):13

2. Harrison DJ, Geller DS, Gill JD, Lewis VO, Gorlick R. Current and future therapeutic approaches for osteosarcoma. Expert Rev Anticancer Ther. 2018; 18(1):39-50

3. Kager L, Tamamyan G, Bielack S. Novel insights and therapeutic interventions for pediatric osteosarcoma. Future Oncol. 2017;13(4):357-68.

4. Arndt CA, Rose PS, Folpe AL, Laack NN. Common musculoskeletal tumors of childhood and adolescence. Mayo Clin Proc. 2012;87(5):475-87.

5. O'Reilly R, Cheung NK, Bowman L, Castle V, Hoffer F, Kapoor N, Kletzel M, Lindsley K, Shamberger R, Tubergen D. NCCN pediatric neuroblastoma practice guidelines. The National Comprehensive Cancer Network. Oncology (Huntingt). 1996;10(12):1813-22

6. Ward WG, Mikaelian K, Dorey F, Mirra JM, Sassoon A, Holmes EC, Eilber FR, Eckardt JJ. Pulmonary metastases of stage IIB extremity osteosarcoma and subsequent pulmonary metastases. J Clin Oncol. 1994;12(9):1849-58.

7. Bauman JE, Duvvuri U, Gooding WE, Rath TJ, Gross ND, Song J, Jimeno A, Yarbrough WG, Johnson FM, Wang L, et al. Randomized, placebo-controlled window trial of EGFR, Src, or combined blockade in head and neck cancer. JCl Insight. 2017;2(6):e90449.

8. Geiger JL, Grandis JR, Bauman JE. The STAT3 pathway as a therapeutic target in head and neck cancer: barriers and innovations. Oral Oncol. 2016; 56:84-92.

9. Kim JS, Kim HA, Seong MK, Seol H, Oh JS, Kim EK, Chang JW, Hwang SG, Noh WC. STAT3-survivin signaling mediates a poor response to radiotherapy in HER2-positive breast cancers. Oncotarget. 2016;7(6):7055-65.

10. Ryu K, Susa M, Choy E, Yang C, Hornicek FJ, Mankin HJ, Duan Z. Oleanane triterpenoid CDDO-me induces apoptosis in multidrug resistant osteosarcoma cells through inhibition of Stat3 pathway. BMC Cancer. 2010;10:187.

11. Yang C, Hornicek FJ, Wood KB, Schwab JH, Choy E, Mankin H, Duan Z Blockage of Stat3 with CDDO-me inhibits tumor cell growth in chordoma. Spine (Phila Pa 1976). 2010;35(18):1668-75

12. Ryu K, Choy E, Yang C, Susa M, Hornicek FJ, Mankin H, Duan Z. Activation of signal transducer and activator of transcription 3 (Stat3) pathway in osteosarcoma cells and overexpression of phosphorylated-Stat3 correlates with poor prognosis. J Orthop Res. 2010;28(7):971-8.

13. Hubbard JM, Grothey A. Napabucasin: an update on the first-in-class Cancer Stemness inhibitor. Drugs. 2017;77(10):1091-103.

14. Li Y, Rogoff HA, Keates S, Gao Y, Murikipudi S, Mikule K, Leggett D, Li W, Pardee AB, Li CJ. Suppression of cancer relapse and metastasis by inhibiting cancer stemness. Proc Natl Acad Sci U S A. 2015;112(6):1839-44.

15. Zhang Y, Jin Z, Zhou H, Ou X, Xu Y, Li H, Liu C, Li B. Suppression of prostate cancer progression by cancer cell stemness inhibitor napabucasin. Cancer Med. 2016;5(6):1251-8

16. Bravo D, Shogren KL, Zuo D, Wagner ER, Sarkar G, Yaszemski MJ, Maran A. 2Methoxyestradiol-mediated induction of Frzb contributes to cell death and autophagy in MG63 osteosarcoma cells. J Cell Biochem. 2017;118(6):1497-504.

17. Yang C, Shogren KL, Goyal R, Bravo D, Yaszemski MJ, Maran A. RNAdependent protein kinase is essential for 2-methoxyestradiol-induced autophagy in osteosarcoma cells. PLoS One. 2013;8(3):e59406.

18. Wimbauer F, Yang C, Shogren KL, Zhang M, Goyal R, Riester SM, Yaszemski MJ, Maran A. Regulation of interferon pathway in 2-methoxyestradioltreated osteosarcoma cells. BMC Cancer. 2012;12:93.

19. Shogren KL, Turner RT, Yaszemski MJ, Maran A. Double-stranded RNAdependent protein kinase is involved in 2-methoxyestradiol-mediated cell death of osteosarcoma cells. J Bone Miner Res. 2007;22(1):29-36.

20. Kennedy AM, Shogren KL, Zhang M, Turner RT, Spelsberg TC, Maran A 17beta-estradiol-dependent activation of signal transducer and activator of transcription-1 in human fetal osteoblasts is dependent on Src kinase activity. Endocrinology. 2005;146(1):201-7.

21. Constantinou C, Clemens MJ. Regulation of translation factors elF4GI and 4E-BP1 during recovery of protein synthesis from inhibition by p53. Cell Death Differ. 2007;14(3):576-85.

22. Maran A, Shogren KL, Yaszemski MJ. The estrogen metabolite 2-methoxyestradiol regulates eukaryotic initiation factor $4 \mathrm{E}(\mathrm{elF} 4 \mathrm{E})$ and inhibits protein synthesis in MG63 osteosarcoma cells. Genes and Diseases. 2016;3:153-8.
23. Yuan J, Ossendorf C, Szatkowski JP, Bronk JT, Maran A, Yaszemski M Bolander ME, Sarkar G, Fuchs B. Osteoblastic and osteolytic human osteosarcomas can be studied with a new xenograft mouse model producing spontaneous metastases. Cancer Investig. 2009;27(4):435-42.

24. Groner B, von Manstein V: Jak Stat signaling and cancer: opportunities, benefits and side effects of targeted inhibition. Mol Cell Endocrinol 2017, 451:1-14.

25. Fossey SL, Liao AT, McCleese JK, Bear MD, Lin J, Li PK, Kisseberth WC, London CA. Characterization of STAT3 activation and expression in canine and human osteosarcoma. BMC Cancer. 2009;9:81.

26. Sellier H, Rebillard A, Guette C, Barre B, Coqueret O. How should we define STAT3 as an oncogene and as a potential target for therapy? Jakstat. 2013; 2(3):e24716.

27. Wen Z, Zhong Z, Darnell JE Jr. Maximal activation of transcription by Stat1 and Stat 3 requires both tyrosine and serine phosphorylation. Cell. 1995: 82(2):241-50

28. Qin HR, Kim HJ, Kim JY, Hurt EM, Klarmann GJ, Kawasaki BT, Duhagon Serrat MA, Farrar WL. Activation of signal transducer and activator of transcription 3 through a phosphomimetic serine 727 promotes prostate tumorigenesis independent of tyrosine 705 phosphorylation. Cancer Res. 2008;68(19):7736-41.

29. Aziz MH, Hafeez BB, Sand JM, Pierce DB, Aziz SW, Dreckschmidt NE, Verma AK. Protein kinase Cvarepsilon mediates Stat3Ser727 phosphorylation, Stat3regulated gene expression, and cell invasion in various human cancer cell lines through integration with MAPK cascade (RAF-1, MEK1/2, and ERK1/2). Oncogene. 2010;29(21):3100-9.

30. Tkach M, Rosemblit C, Rivas MA, Proietti CJ, Diaz Flaque MC, Mercogliano MF, Beguelin W, Maronna E, Guzman P, Gercovich FG, et al. p42/p44 MAPKmediated Stat3Ser727 phosphorylation is required for progestin-induced full activation of Stat3 and breast cancer growth. Endocr Relat Cancer. 2013; 20(2):197-212.

31. Oi T, Asanuma K, Matsumine A, Matsubara T, Nakamura T, lino T, Asanuma Y, Goto M, Okuno K, Kakimoto T, et al. STAT3 inhibitor, cucurbitacin I, is a novel therapeutic agent for osteosarcoma. Int J Oncol. 2016;49(6):2275-84

32. Clemens MJ. Targets and mechanisms for the regulation of translation in malignant transformation. Oncogene. 2004;23(18):3180-8.

33. El-Naggar AM, Sorensen PH. Translational control of aberrant stress responses as a hallmark of cancer. J Pathol. 2018:244(5):650-66.

34. Ramon YCS, Castellvi J, Hummer S, Peg V, Pelletier J, Sonenberg N. Beyond molecular tumor heterogeneity: protein synthesis takes control. Oncogene. 2018.

35. Siddiqui N, Sonenberg N. Signalling to elF4E in cancer. Biochem Soc Trans. 2015:43(5):763-72

36. Yu H, Kortylewski M, Pardoll D. Crosstalk between cancer and immune cells: role of STAT3 in the tumour microenvironment. Nat Rev Immunol. 2007;7(1):41-51.

37. Hutchins AP, Diez D, Miranda-Saavedra D. Genomic and computational approaches to dissect the mechanisms of STAT3's universal and cell typespecific functions. Jakstat. 2013;2(4):e25097.

38. Dodd KM, Yang J, Shen MH, Sampson JR, Tee AR. mTORC1 drives HIF1alpha and VEGF-A signalling via multiple mechanisms involving 4E-BP1, S6K1 and STAT3. Oncogene. 2015;34(17):2239-50.

Ready to submit your research? Choose BMC and benefit from

- fast, convenient online submission

- thorough peer review by experienced researchers in your field

- rapid publication on acceptance

- support for research data, including large and complex data types

- gold Open Access which fosters wider collaboration and increased citations

- maximum visibility for your research: over $100 \mathrm{M}$ website views per year

At BMC, research is always in progress.

Learn more biomedcentral.com/submission 